\title{
COVID-19 Y ESTADO AUTONÓMICO
}

\author{
Manuel Aragón Reyes \\ Catedrático emérito de Derecho Constitucional. \\ Magistrado emérito del Tribunal Constitucional
}

Cómo citar este artículo / Citation: Aragón Reyes, M. (2021). Covid-19 y Estado Autonómico.

Tudela Aranda, J. (coord.)

Estado Autonómico y covid-19,

Colección Obras colectivas, Fundación Manuel Giménez Abad, Zaragoza.

DOI: https://doi.org/10.47919/FMGA.OC21.0204

SUMARIO: I. ACLARACIÓN - II. REBROTE DE LA PANDEMIA Y TRASLADO DEL PROTAGONISMO A LAS COMUNIDADES AUTÓNOMAS - III. EL CASO DE MADRID COMO MUESTRA DEL CONFUSO ENTENDIMIENTO DE LAS COMPETENCIAS - IV. LA DECLARACIÓN DE ESTADO DE ALARMA DE 25 DE OCTUBRE DE 2020 Y SU PRÓRROGA - V. EL ESTADO AUTONÓMICO: ¿FRACASO O INAPLICACIÓN DEL MODELO?

\section{ACLARACIÓN}

Estas páginas sólo pretenden apuntar, con brevedad, algunas reflexiones constitucionales acerca de la situación del Estado autonómico en las actuaciones llevadas a cabo para adoptar medidas eficaces frente a la pandemia que desde hace tiempo nos aqueja. Adelanto ya una consideración de carácter general: uno de los problemas principales que, a mi juicio, se han puesto de manifiesto es la decisión de descargar en las comunidades autónomas esa tarea, pues, respecto de ella, ni el Estado deja de tener competencias de obligatorio ejercicio ni los poderes autonómicos las poseen para adoptar, por sí solos, las medidas que la grave situación requiere. 


\section{REBROTE DE LA PANDEMIA Y TRASLADO DEL PROTAGONISMO A LAS COMUNIDADES AUTÓNOMAS}

Una vez pasado el periodo del estado de alarma de ámbito nacional, durante el cual, desde el 14 de marzo al 21 de junio, el Estado asumió la dirección centralizada para hacer frente a la covid-19, la gravedad de la pandemia volvió a surgir, pese a la imprudente afirmación gubernamental del que el virus "se había derrotado". Ante la nueva situación, y a diferencia de lo que antes se hizo, el Gobierno estatal optó por descargar en las comunidades autónomas la responsabilidad de adoptar las medidas que considerasen necesarias para resolver la crisis sanitaria, provocando, hasta ahora ${ }^{1}$, una variedad de actuaciones caracterizadas por la descoordinación, la confusión e, incluso, el enfrentamiento territorial en algunos casos, que no contribuyen a la eficacia de las decisiones autonómicas que se han ido tomando. Uno de los problemas que están en la raíz de esta situación es, me parece, la inadecuación de combatir un mal general, que se extiende (con mayor o menor gravedad) en todo el territorio nacional, con medidas territorialmente limitadas al ámbito de cada comunidad autónoma. La pandemia, se ha dicho con frase gráfica, no conoce fronteras, menos aún dentro del territorio estatal.

El otro problema ya no es sanitario, sino netamente jurídico, aunque uno y otro están enlazados. Tiene que ver con las competencias respectivas del Estado y las comunidades autónomas. Para combatir la situación sanitaria que, desde el pasado julio, se está reproduciendo, el Estado, de acuerdo con las reglas constitucionales, tiene unas competencias irrenunciables, de ejercicio obligatorio, que no puede endosar a las Comunidades Autónomas. Y aquí nos hemos encontrado con determinadas afirmaciones del Gobierno estatal que no casan con la realidad de nuestro ordenamiento jurídico. Así se ha dicho (por el Presidente del Gobierno) que un nuevo estado de alarma sólo se declararía si lo solicitasen, para su territorio, las comunidades autónomas, con desconocimiento de que esa declaración, según determinan la Constitución (en adelante, CE) y la Ley Orgánica 4/1981, es de la exclusiva responsabilidad del Gobierno estatal, que puede determinar el ámbito, nacional o territorialmente

\footnotetext{
${ }^{1} 4$ de diciembre de 2020, momento en que se redacta este trabajo. 
fundación

Manuel Giménez Abad

deEstudios Parlamentariosydel Estado Autonómico

limitado, de tal declaración, y que la solicitud de una comunidad autónoma (prevista en la LO 4/1981) ni es preceptiva (sino facultativa) ni es vinculante.

También se ha dicho, por cualificados portavoces del Gobierno, de manera sorprendente, que el Estado ordinariamente "carece de competencias en sanidad y educación porque ambas están transferidas por completo a las comunidades autónomas". Tal afirmación es completamente errónea, pues la CE atribuye al Estado competencias exclusivas en ambas materias, competencias que son, como se ha dicho, irrenunciables.

Así el art. 149.1.16 atribuye al Estado las "bases y coordinación general de la sanidad", lo que le obliga a, y no solamente le faculta para (STC 98/2004, FJ 7 ), adoptar una regulación uniforme y de vigencia en todo el territorio nacional destinada a la preservación de los intereses generales que en la sanidad concurren, mediante normas legales $\mathrm{y}$, excepcionalmente, reglamentarias (SSTC 69/1988, FJ 5, 54/1990, FJ 3, 233/1999, FJ 5, entre otras) e incluso, para adoptar "decisiones y actuaciones" "que tienen como objeto la regulación inmediata de situaciones concretas" (STC 98/2004, FJ 7). Y el art. 149.1.30 a CE atribuye al Estado, en materia educativa, además de la regulación de las condiciones de obtención y homologación de títulos académicos y profesionales, las "normas básicas para el desarrollo del artículo 27 de la Constitución", es decir, del derecho a la educación que permitan disfrutarlo todos los españoles en condiciones de igualdad, normas que no sólo se contendrán en las leyes orgánicas (reserva establecida por el art. 81.1 CE) sino que podrán también incluirse en reglamentos "cuando sea obligado y necesario para completar" ese "desarrollo normativo" (entre otras, STC 101/1991, FJ 3, con cita de la STC 77/1985).

En consecuencia, ni el Estado puede rehuir su responsabilidad en la adopción de medidas sanitarias y educativas para hacer frente a la pandemia, ni las comunidades autónomas, que sí tienen reconocida competencia para "desarrollar" las bases estatales, pueden sustituir la obligación de regulación (e incluso a veces de ejecución) básica que sólo al Estado corresponde. La llamada "cogobernanza", que puede indicar una loable actuación conjunta del Estado y las comunidades autónomas en estos tiempos de crisis, no puede inducir a la confusión de que el Estado sólo puede actuar a través de tal colaboración, ya que tiene determinadas competencias exclusivas que, por sí 
fundación

Manuel Giménez Abad

deEstudios ParlamentariosydelEstado Autonómico

solo, y no supeditado a la voluntad concorde de una comunidad autónoma (o de todas ellas), ha de ejercer, necesariamente.

Competencias exclusivas del Estado que también incluyen la capacidad normativa prevista en los arts. 149.1.1 ${ }^{\text {a }}$ y 149.1.13 a CE (un precepto, este último, que permite además, aunque excepcionalmente, la adopción de actos ejecutivos). A lo que se une la potestad estatal de coordinación (señalada incluso expresamente en el art. 149.1.16ª en relación con la sanidad) que, por cierto, no se ha usado con la amplitud debida, pero que sólo abarca los supuestos en que tanto el Estado como las comunidades autónomas actúen en el ámbito de sus respectivas competencias y no cuando cuándo aquellas no las tengan respecto de decisiones que sólo el Estado puede, en exclusiva, adoptar. No me estoy refiriendo ahora a las medidas excepcionales, obviamente de exclusiva responsabilidad estatal, sino a las que permite el Derecho de la normalidad, que, además de atribuir al Estado la competencia para establecer un mínimo común normativo uniforme en todo el territorio, le apodera para limitar derechos fundamentales (más exactamente, los previstos en la Sección $1^{\text {a }}$ del Capítulo $2^{\circ}$ del Título I CE) mediante leyes orgánicas e incluso, en el caso de la libertad de empresa, mediante leyes ordinarias. Esas decisiones normativas no pueden trasladarse a las comunidades autónomas.

Porque lo que en realidad ha sucedido es que la abstención del Estado en el cumplimiento diligente de sus competencias frente a la nueva ola de la pandemia, endosándoselas a las comunidades autónomas, ha propiciado que estas hayan adoptado determinadas y muy intensas medidas limitativas de derechos fundamentales (a la libre circulación, a la libre reunión y a la libertad de empresa, entre otros) para las que es muy dudoso que tengan competencias, sin que esa cuestión esté resuelta, creo, por las previsiones contenidas en el art. 26 de la Ley 14/1986, General de Sanidad, en los arts. 1 y 3 de la Ley Orgánica 3/1986, de Medidas Especiales en materia de Salud Pública y en el art. 65 de la Ley 16/2003, de Cohesión y Calidad del Sistema Nacional de Salud. Además, las posibles actuaciones autonómicas ante crisis sanitarias, en principio previstas para restricciones individualizadas, con previa autorización de la autoridad judicial, es muy discutible que quepan para limitaciones de derechos indiscriminadas como las que están adoptando determinadas comunidades autónomas, pese a que, de manera harto discutible, la reforma de la LJCA producida por la Ley 3/2020, de 28 de 
septiembre, haya extendido la autorización judicial a los supuestos en que los destinatarios de las restricciones de derechos no "estén identificados individualmente".

Esta reforma, repentina y poco meditada, de la LJCA plantea al menos dos problemas. El primero es su posible contradicción con la función constitucional del Poder judicial, cuyas competencias (incluidas las que por ley puedan serle atribuidas según el art. 117.4 CE) no pueden invadir las que son propias del poder legislativo y el poder ejecutivo, en este caso dictar normas generales (de ámbito nacional o territorial). En definitiva, el poder judicial no puede co-legislar, que es lo que sucede si para que una norma pueda entrar en vigor primero se exige la previa autorización judicial. El segundo problema es que una norma de carácter procesal, como es la previsión legal de ese control previo, no puede servir como título atributivo de competencia material al poder (en este caso autonómico) del que emana la medida susceptible de control.

Pero es que, además, tales limitaciones autonómicas de derechos, indiscriminadas o generales aunque circunscritas a determinadas zonas o territorios, si dados su ámbito y su notable intensidad restrictiva tuviesen un carácter excepcional, como es el caso de algunas de ellas, ni siquiera, al menos en la situación actual de nuestro ordenamiento, podrían ser adoptadas hoy por el propio Estado de manera ordinaria, y menos aún, en esos casos, por los poderes autonómicos, pues, a mi juicio, no cabrían dentro del Derecho de la normalidad, sino del Derecho de la excepción: ya sea mediante la declaración del estado de alarma, si se trata únicamente de limitaciones de derechos, o del estado de excepción, si estos derechos se suspendieran. Realmente, y de modo insólito, estamos asistiendo a una especie de "estados de alarma" no adoptados por el Gobierno estatal sino por las comunidades autónomas, con evidente desvío de lo constitucionalmente previsto.

Lo que acaba de decirse requiere una explicación sobre el estado de alarma. A diferencia de lo que sucede con el estado de excepción, única vía para suspender derechos, en el estado de alarma las limitaciones de derechos que puede establecer están supeditadas a que con las previstas en el Derecho de la normalidad no fuera posible (art. 1.1 LO 4/1981) hacer frente con eficacia a la situación crítica que se haya producido. De manera que, si el Derecho ordinario habilitase para la adopción de las necesarias limitaciones de derechos, sólo podría declararse el estado de alarma si también fuese 
necesaria la centralización territorial de competencias (algo que, eso sí, a través del Derecho ordinario no puede conseguirse). Nuestro problema, como después se verá, es que el actual Derecho de la normalidad no contiene (ni en marzo de 2020 ni ahora) la habilitación constitucionalmente requerida para las limitaciones de derechos fundamentales adoptadas por las medidas ordinarias (no excepcionales) que se han tomado para hacer frente a la pandemia. De manera que, mientras la legislación ordinaria no se reforme, tales limitaciones de derechos sólo a través del estado de alarma pueden, a mi juicio, establecerse.

\section{EL CASO DE MADRID COMO MUESTRA DEL CONFUSO ENTENDIMIENTO DE LAS COMPETENCIAS}

Lo sucedido en octubre en relación con la Comunidad de Madrid es un buen ejemplo del problema al que acaba de aludirse, que ha conducido a que el Tribunal Superior de Justicia, por Auto 128/2020, de 8 de octubre, haya rechazado las medidas adoptadas por la Orden de la Consejería de Sanidad 1273/2020, de 1 de octubre, en cumplimiento de la Orden comunicada de 30 de septiembre de 2020 del Ministerio de Sanidad (sin publicidad en el BOE, fórmula que se viene usando pero que no deja de ser criticable) por la que se aprueba la Declaración de Actuaciones Coordinadas en Salud Pública (prevista en el art. 65 de la Ley 16/2003) a propuesta de la Comisión Interterritorial del Sistema Nacional de Salud (publicada en el BOE por Resolución del Secretario de Estado de Sanidad el mismo día 30 de septiembre).

Las razones del Auto para rechazar la autorización judicial requerida por la Consejería se basan en que el art. 65 de la Ley 16/2003 no presta cobertura para las restricciones indiscriminadas de derechos que en la Orden autonómica se adoptan (aunque fuesen requeridas por la Orden comunicada del Ministerio de Sanidad y propuestas por la Comisión Interterritorial), así como que tampoco la presta el Real Decreto-ley 21/2020 (sobre posibles medidas ante el riesgo de rebrotes de la pandemia). El Tribunal Superior de Justicia advierte que, en apoyo de la necesidad, cierta, de actuar ante una situación, como la que se da en la Comunidad de Madrid, lo que no cabe es hacerlo fuera del Derecho, cuanto resulta que ese riesgo puede combatirse a través de los instrumentos constitucionalmente previstos para ello. Instrumentos que (como 
apunta el Auto) son de la exclusiva competencia del Estado. En resumen, que sólo el Estado puede, de modo ordinario o excepcional, imponer ese tipo de restricciones de los derechos fundamentales.

Es cierto que otros tribunales (e incluso, anteriormente, el mismo que ha dictado el Auto) han producido, en supuestos similares, resoluciones distintas, apreciando que las medidas autonómicas podían tener cobertura en la Ley Orgánica 3/1986, en lugar de en la Ley 16/2003, que fue la vía señalada en esta nueva ocasión por el Gobierno estatal. Esta disparidad de decisiones judiciales, que pone de manifiesto un serio problema de incoherencia, e incluso de inseguridad jurídica, es expresiva también de la confusión ante el problema jurídico principal sobre la cobertura legal, pues a mi juicio, siendo cierto que la Ley 16/2003 no ofrece cobertura para la limitación autonómica de derechos fundamentales, tampoco la ofrece, como antes apunté, la Ley Orgánica 3/1986 por su falta de determinación acerca de las condiciones esenciales a que han de someterse las posibles limitaciones de derechos (limitaciones a las que, por cierto, ni siquiera alude), sin que baste con señalar únicamente la causa (graves problemas sanitarios) que avalaría las actuaciones públicas.

No puede existir, en materia de limitación de derechos fundamentales, una especie de habilitación en blanco efectuada por la ley orgánica a favor de otras normas (según doctrina constante del TC), y menos a simples órdenes de las consejerías autonómicas. Además de que, como acaba de señalarse, tal habilitación para limitar derechos no está prevista, ni siquiera de manera expresa, en la propia LO 3/1986. En definitiva, nuestro ordenamiento constitucional no permite una especie de "ley de plenos poderes" para la adopción de "cualquier medida" que las autoridades públicas consideren necesaria para hacer frente a una crisis sanitaria. Ni el fin justifica los medios, ni los derechos fundamentales pueden estar supeditados al viejo lema salus publica suprema lex esto. El Estado no está inerme, por supuesto, y facilita sobradamente los instrumentos jurídicos necesarios para combatir dicha crisis, eso sí, respetando las reglas y procedimientos exigidos: habilitaciones legales suficientes y, cuando ello no existe, declaración de los estados excepcionales. Ambos instrumentos son de exclusiva y obligada titularidad estatal, que no puede ser transferida a las comunidades autónomas.

El Auto del TSJ, al privar de eficacia a las medidas adoptadas por la Comunidad de Madrid, ha conducido al Gobierno estatal a declarar, al día 
siguiente, el estado de alarma para hacer frente a la gravedad de la situación mediante el Real Decreto 900/2020, de 9 de octubre, que reproduce el ámbito (el municipio de Madrid y otros 8 de la Comunidad Autónoma) y las medidas que el TSJ rechazó. Al margen de la crítica política que pudiera hacerse acerca de las circunstancias y la oportunidad de esta actuación del Gobierno, esa declaración de alarma de ámbito territorial restringido creo que está correctamente amparada en las normas reguladoras de nuestro Derecho excepcional, pero ha sido precedida de un enfrentamiento nada ejemplar entre el Gobierno estatal y el Gobierno autonómico, así como seguida de la denuncia política por este de supuestos agravios o discriminaciones territoriales basadas en la comparación de los datos de Madrid con los de otros municipios u otras comunidades autónomas. No es este, pues, el mejor modo de hacer frente a los gravísimos riesgos, de muy diverso orden, que la pandemia origina.

\section{LA DECLARACIÓN DE ESTADO DE ALARMA DE 25 DE OCTUBRE DE 2020 Y SU PRÓRROGA}

Con el objeto de hacer frente a la gravísima situación actual originada por una pandemia cada vez más intensa y extendida en todo nuestro territorio, y en vista de que no se han llevado a cabo las reformas de la legislación ordinaria que hubieran permitido adoptar otras medidas distintas, el Gobierno ha decidido, por Real Decreto 926/2020, de 25 de octubre, declarar un nuevo estado de alarma de ámbito nacional, único modo, pues, de necesaria utilización para establecer las limitaciones de derechos que se requieren. Sin embargo, esta nueva declaración, dado su contenido, suscita serios problemas.

El primero, que está enlazado con todos los demás, reside en que, una vez expresado en el RD que la autoridad competente es el Gobierno de la Nación, también determina que tal autoridad competente será, igualmente, por delegación del Gobierno nacional, el presidente de cada comunidad autónoma. Ello no deja de entrar en contradicción con lo dispuesto en el art. 7.1 LO 4/1981, que sólo habilita tal delegación "cuando la declaración afecte exclusivamente a todo o parte del territorio" de esa comunidad, no en el supuesto, como el de ahora, de que el estado de alarma es de ámbito nacional, en cuyo caso el art. 7.1 dispone, contrario sensu, que la autoridad competente 
es el Gobierno estatal, lo que resulta lógico con la necesaria dirección unitaria, centralizada, de la aplicación en todo el territorio de las medidas adoptadas.

Ese problema se proyecta en el siguiente, relativo a las competencias que se atribuyen a las comunidades autónomas para decidir, dentro del marco de restricciones de derechos que el RD de declaración señala, la efectividad de las mismas. Los problemas jurídicos que ello plantea son múltiples, como veremos. Se facilita que, a juicio de cada comunidad autónoma, las restricciones de derechos que el RD señala puedan se moduladas (dentro de unos límites) por la autoridad autonómica (arts. 5, 6 y 7 del RD), lo que originaría una variedad territorial de medidas poco coherente con la necesidad de homogeneización nacional de las respuestas públicas frente a la pandemia y, lo que es más grave, se atribuye las comunidades autónomas la decisión efectiva sobre las medidas a adoptar, lo que se deriva implícitamente del tenor del art. 5.2 el RD (cuando se habla de que la autoridad competente delegada correspondiente es la que podrá "determinar", con eficacia inmediata, en su ámbito territorial la limitación de la libertad de circulación de personas en horario nocturno) y explícitamente se dispone en el art. 9 del RD acerca de las medidas enunciadas en los arts. 6, 7 y 8 (los llamados confinamientos perimetrales y las limitaciones del derecho de reunión en los espacios públicos y privados), que sólo serán efectivas en las comunidades autónomas (como expresamente se dice en dicho art. 9) "cuando la autoridad competente delegada lo determine".

En definitiva, en lugar de una declaración efectiva y de inmediata vigencia del estado de alarma, que es, a mi juicio lo que la Constitución y la LO 4/1981 disponen, se ha acudido a una especie de estado de alarma como norma de habilitación para que sean, en realidad, las comunidades autónomas, aunque dentro de unos determinados parámetros (flexibles, e incluso sin predeterminación de su comienzo temporal), las que efectúen esa "declaración". Estados de alarma, pues, de determinación autonómica, que no es, insisto, lo que la Constitución y la LO 4/1981 han dispuesto. Es el Gobierno de la Nación el que ha de "determinar" (art. 116.2 CE y art. 6.2 LO) "los efectos" del estado de alarma, no, de ninguna manera, las autoridades autonómicas. La "autoridad competente" prevista en el art. 7 LO 4/1981 lo es para "ejecutar" las medidas establecidas por la declaración del estado de alarma, no para "determinarlas". 
Otro problema originado por el RD de declaración se refiere a la atribución a los simples decretos previstos en el art. 8.2 de la LO 4/1981, de la capacidad de "modificar lo establecido" en el decreto de declaración (disposición final primera del RD de declaración). La llamada que en dicha disposición se hace (como en el art. 8.2 LO) a que de tales decretos se deberá dar cuenta al Congreso de los Diputados sólo significa eso (una información al Congreso), pero nunca puede valer para modificar el estado de alarma, que sólo por su correspondiente decreto de prórroga podrá hacerse. Sólo los decretos de declaración y prórroga pueden establecer limitaciones de derechos, porque sólo estos decretos tienen la fuerza de la ley, y no estos decretos del art. 8.2 LO, que no la tienen.

Esto último nos conduce al examen de una afirmación contenida en le exposición de motivos del RD 929/2020 donde se expresa que la gravedad de la pandemia requiere de medidas excepcionales "durante un periodo que necesariamente deberá ser superior al plazo de quince días establecido para la vigencia de este real decreto, por lo que resultará imprescindible prorrogar esta norma por un periodo estimado de seis meses". Esta pretensión sólo puede ser de naturaleza política, nunca jurídica, pues de la Constitución y de la LO 4/1981 se desprende que las prórrogas han de serlo por plazo no superior a 15 días. De manera que, en este caso, al finalizar la declaración el 9 de noviembre, como expresa correctamente el art. 4 del RD (ateniéndose a lo dispuesto en la CE y la LO), no cabe prorrogar el estado de alarma por seis meses (o cinco y medio, si se cuentan los 15 días iniciales). El mismo art. 4 reconoce, también correctamente, que la fecha del 9 de noviembre lo es "sin perjuicio de las prórrogas que puedan establecerse". Prórrogas que, jurídicamente, y no importa repetirlo, no pueden ser superiores a 15 días. Si el estado de alarma pudiera, y debiera, prolongarse por más tiempo, sería necesario, pues, obtener la preceptiva autorización del Congreso cada 15 días.

No obstante, esa intención "política" del Gobierno de que el estado de alarma se prorrogue durante seis meses, enunciada en la exposición de motivos del $\mathrm{RD}$, quizás se ha proyectado también en la parte dispositiva de esa norma, al prever su art. 14 que, "en caso de prórroga, el Ministro de Sanidad comparecerá quincenalmente ante la Comisión de Sanidad y Consumo del Congreso de los Diputados para dar cuenta de la aplicación de las medidas previstas en este Real Decreto". Pese a la coincidencia (hay que pensar, deliberada) de fechas, la correcta interpretación de nuestro ordenamiento viene 
a disipar, sin embargo, aquella sospecha, pues ni la Constitución ni la LO 4/1981 permiten que la loable comparecencia, cada 15 días, del Ministro ante una Comisión, pueda sustituir a la prórroga, esto es, a la necesaria autorización del Pleno del Congreso, cada 15 días, para que el estado de alarma pueda continuar.

En nuestro sistema constitucional, la participación del Parlamento en las decisiones sobre el Derecho de excepción no consiste sólo en que se le dé cuenta de la aplicación de las medidas (a efectos informativos y de debate), sino en que se requiera necesariamente de su voluntad (exactamente la del Congreso de los Diputados) para que periódicamente decida si las medidas excepcionales continúan o no o si necesitan ser modificadas. Por ello, en el estado de alarma tal periodicidad, que lo es de 15 días, no puede ser eliminada, ni siquiera por acuerdo de la propia Cámara, ya que es una garantía constitucional cuya vigencia no está a la libre disposición de la mayoría parlamentaria.

Pese a que nuestro Derecho de excepción no lo permite, por las razones dadas, sin embargo, lo cierto es que tal prórroga de seis meses, ya anunciada por el decreto de declaración, se ha llevado a efecto, autorizada por el Congreso el 29 de octubre y declarada por el Real Decreto 956/2020, de 3 de noviembre. La infracción constitucional, a mi juicio, es evidente, y no cabe excusarla acudiendo a la argumentación de que el Derecho constitucional de excepción había quedado obsoleto por no haber podido prever, en 1978, una situación como la ocasionada por esta grave pandemia. Si así hubiera sido, la solución no es quebrantar la Constitución, sino reformarla, pero sucede que ello ni siquiera es necesario, pues las previsiones constitucionales sobre el estado de alarma, correctamente interpretadas, permitían perfectamente haber adoptado medidas eficaces para hacer frente a esta crisis: ejerciendo el Estado sus competencias irrenunciables, en lugar de delegarlas, indebidamente, en las comunidades autónomas, y sometiendo, cada 15 días las prórrogas que fueran necesarias a la preceptiva autorización del Congreso, lo que permitiría, además, modular las medidas según las circunstancias cambiantes en cada momento y en cada parte del territorio nacional.

De manera lamentable, esta última declaración del estado de alarma y su prórroga vienen a ser prolongación de una política desacertada, consistente en el endoso a las comunidades autónomas de las decisiones, inevitablemente 
restrictivas de derechos, para hacer frente a la pandemia. La confusión de competencias continúa, así como la huida, por la autoridad estatal, de las responsabilidades propias. Sus consecuencias me temo que seguirán siendo la disparidad de trato entre los españoles, las contradicciones entre las medidas adoptadas para los distintos territorios y, lo peor de todo, la ineficacia para combatir con éxito las gravísimas consecuencias sanitarias, económicas y sociales que la pandemia ha producido y seguirá produciendo.

La tendencia, que viene mostrándose en los últimos tiempos, a no respetar debidamente la Constitución parece que se ha agudizado. Por lo demás, no sería cierta la opción entre "Constitución o salud", porque la salud puede perfectamente protegerse de modo constitucional: a través del Derecho ordinario y, si fuera preciso, a través del Derecho de excepción. Eso sí, cumpliendo fielmente lo que, en ambos planos, la Constitución ha dispuesto.

\section{EL ESTADO AUTONÓMICO: ¿FRACASO O INAPLICACIÓN DEL MODELO?}

Todos los problemas que se han venido examinando conducen, de manera inevitable, a una reflexión general acerca del Estado autonómico. Del mismo modo que al comienzo de la crisis sanitaria se expresaron opiniones sobre la inadecuación de nuestro Derecho de excepción a la nueva realidad de la pandemia provocada por el coronavirus, ahora, cuando esta ha vuelto a surgir, se ha extendido la idea de que la organización de nuestro Estado autonómico no es la más adecuada para hacerle frente. Ambas opiniones merecen ser rebatidas. Respecto de la primera ya se ha explicado más atrás su inconsistencia

Y lo mismo sucede con el ordenamiento del Estado autonómico. El caos, la desorganización y los problemas de eficacia generados por el traslado a las comunidades autónomas de la responsabilidad de hacer frente a los rebrotes del coronavirus no muestran las falencias del modelo territorial, sino la inadecuada aplicación del mismo. Al margen de que ese modelo deba de ser reformado para dotarlo de mayor eficacia, algo que es claro, lo cierto es que el modelo actual no tenía por qué haber producido la situación antes descrita si se hubiese aplicado de manera correcta. Es decir, si el Estado se hubiera hecho 
cargo de las responsabilidades a que el modelo le obliga. En resumidas cuentas, si el poder estatal hubiese utilizado las competencias que tiene (entre ellas la de reformar la legislación sanitaria para habilitar correctamente posibles limitaciones de derechos y la de acudir, cuando es necesario, al estado de alarma sin desfigurarlo) en lugar de endosar a las comunidades autónomas una actuación que excede de las competencias de estas.

Estas reflexiones son trasladables a un ámbito más general del funcionamiento del Estado. A veces se imputan al modelo constitucional carencias que no obedecen a sus deficiencias normativas, sino, en la mayoría de las ocasiones, a su inadecuada aplicación. Muchos de los problemas que se achacan a nuestro Estado constitucional democrático y autonómico no son consecuencia de las normas que lo regulan, sino de que estas no se cumplen. De acuerdo con las previsiones constitucionales, y con la jurisprudencia del Tribunal Constitucional, determinados problemas que nos aquejan (y no sólo los derivados de la pandemia) podrían haber sido encauzados de mejor manera si los poderes públicos actuasen de conformidad con el ordenamiento constitucional. Ha sido la práctica desviada de esas previsiones normativas la que nos ha conducido a una situación institucional y social lamentable.

Por ello, en tiempos de aflicción, como los de ahora, sin perjuicio de auspiciar reformas estructurales de nuestro ordenamiento constitucional, quizás lo más perentorio sea, probablemente, actuar de conformidad con él. No tenemos un Estado estructuralmente fallido. Lo que tenemos son unos poderes públicos que fallan en el cumplimiento de sus obligaciones por no acudir a los resortes que la Constitución les brinda. Ese es uno de nuestros principales problemas. En lo que se refiere al Estado autonómico, lo que procede es que los diversos poderes públicos actúen con las competencias y la responsabilidad que ese Estado les demanda. Ello no asegura la victoria sobre la pandemia, pero al menos permitiría hacerle frente con mayores probabilidades de éxito. 